\title{
Toilet training children: when to start and how to train
}

\author{
Darcie A. Kiddoo MD
}

$\mathrm{T}$ oilet training is felt to be a natural process that occurs with development, yet very little scientific information is available for the physicians who care for children. In reality, toilet training is a complex process that can be affected by anatomic, physiologic and behavioural conditions. Accepted norms of toilet training relate more to cultural differences than scientific evidence. Despite this, parents continue to approach their family physicians and pediatricians for advice about toilet training. This article summarizes the most common methods of toilet training and provides an overview of the literature in an attempt to help physicians provide advice to their patients.

Methods of toilet training have fluctuated over the last 100 years from passive and lacking in structure, to coercive and regimented, to childoriented and semistructured. The first description of a standardized method of toilet training was published in 1962 by Brazelton. He developed a "child readiness" approach, which was childfocused and unregimented. The children started training at 18 months of age, and, in a group of 1170 children, daytime continence was achieved by a mean age of 28.5 months. ${ }^{1}$ Children were considered "ready" to start training when they were physiologically capable of the process and when the child and parent were emotionally ready. Both the child and parent needed to be interested and had to be in a social situation where toilet training was possible. The child required some degree of bowel and bladder control, identified by the ability to suppress reflexes of the bladder and bowel, and had to have the neurologic capability to cooperate, as seen in children who can perform basic gross motor skills.

Spock discussed toilet training in Baby and Child Care, published in 1968. Like Brazelton, Spock recommended a child-oriented approach, starting when the child displayed signs of readiness. ${ }^{2} \mathrm{He}$ was opposed to absolute rules that could result in behavioural problems.

In 1973, Foxx and Azrin published a method that was structured and parent-oriented. ${ }^{3}$ This method still required the child to be physiologically and psychologically ready. The authors used predefined tasks to ascertain whether the child was ready. Once readiness was determined, a four-step method was used that included increased intake of fluids, scheduled toileting, positive reinforcement and overcorrection of accidents. Two small studies of 34 and 49 children used this method, and children who had passed the readiness test were trained in a mean of 4.5 hours. ${ }^{3.4}$

Other methods that have emerged include the very early approach of assisted toilet training in infants, ${ }^{5}$ operant conditioning and the daytime wetting alarm. ${ }^{6}$ Early training of infants begins when the infant is two to three weeks of age. The infant is placed on the toilet after a meal and whenever the parent thinks the child may need to evacuate his or her bowel or bladder. The parent makes a noise that is linked to elimination and conditions the child to evacuate with the noise. Variations in this method of toilet training of infants exist, including the three-phase approach and elimination communication. Benefits of these methods include cost savings, limitation of pollution and improvement of comfort. There are no studies evaluating these methods.

Operant conditioning is a component of other training methods; however, this specific approach is based on both positive and negative reinforcement. Dryness is rewarded with affection, toys or candy, and accidents are dealt with through punishment or lack of positive attention. The daytime wetting alarm is a device that is attached to the diaper and rings when wet. Parents are asked to place their child on the toilet when the device rings.

In 2006, the Agency for Healthcare Research and Quality published a systematic review evaluating the evidence for methods of toilet training.? Only three trials included in the review involved healthy children, and none of those three trials directly compared the two most common methods by Brazelton, and Foxx and Azrin. In a randomized trial involving 71 children, the method by Foxx and Azrin performed better than the method by Spock. ${ }^{8}$ Another trial randomly assigned 406

\section{- Ker POINTS}

- There is little evidence supporting specific methods of toilet training.

- Toilet training should be started when both the child and parent are willing and able to participate.

- A positive, consistent approach to toilet training is unlikely to cause long-term harm. 
children to groups and found that the avoidance of negative terms in relation to defecation in addition to the Brazelton method was better than the Brazelton method alone. 9 In a randomized study involving only 10 children, the method by Foxx and Azrin was used. Children whose mothers were supervised by an experienced trainer had improved results compared with children whose mothers only read a book. ${ }^{10}$

Since the 2006 systematic review, ${ }^{7}$ only one small trial has been published that compared the daytime wetting alarm with simple timed toileting; the study found the alarm to be more successful than simple timed toileting. ${ }^{6}$

Despite the lack of evidence, the American Academy of Pediatrics and the Canadian Paediatric Society recommend a child-oriented approach based on expert opinion. They advise starting when the child is 18 months of age and suggest that the child must be interested in the process. ${ }^{11,12}$

Adverse events that are discussed in association with toilet training include toileting refusal for stool, withholding of stool, encopresis, hiding while defecating and urinary disorders of elimination. Only a few studies identified in the 2006 systematic review addressed adverse outcomes. ${ }^{7}$ Brazelton reported a $1.4 \%$ incidence of problems after five years of age using his childoriented method, and Fox and Azrin did not report on adverse events. ${ }^{1,3}$ One retrospective case-control study of 4332 children found that children who had symptoms of incontinence or infections were more likely to have been rewarded and punished during toilet training, whereas children with no symptoms of the lower urinary tract were more likely to have been encouraged by their parents to try again later. ${ }^{13}$

A common question asked is when to begin toilet training. Bakker and colleagues and Taubman and coauthors found a higher incidence of incontinence and urinary tract infections when children were trained later (Bakker $>18$ mo; Taubman $>42$ mo). ${ }^{9,13}$ Blum and colleagues concluded that toilet training at a younger age (18-26 mo) was associated with a longer training interval but no adverse events..$^{14}$ More recently, a case-control study and found that toilet training after 32 months was associated with a higher incidence of urge incontinence. ${ }^{15}$ However, the mean ages may not be clinically significant at 31.7 months in children with incontinence and 28.7 months in controls.

Several groups of authors have found that age at toilet training was not a predictor in children with urologic problems. ${ }^{16-18}$ Finally, Joinson and colleagues, who published the only study using regression analysis to evaluate age at toilet training, found that training after 24 months was associated with higher odds of daytime wetting. ${ }^{19}$

Various methods exist to toilet train children and most start with an evaluation of the readiness of the child. There is no level- 1 evidence to prove which method is best. There is little information about long-term harm associated with toilet training. However, there is some evidence to suggest that more disorders of elimination may develop in children who toilet train late. In the absence of evidence, the treating physician must rely on expert opinion and should turn to the Canadian Paediatric Society and the American Academy of Pediatrics for advice for patients that is unlikely to cause harm.

\section{References}

1. Brazelton TB. A child-oriented approach to toilet training. Pediatrics 1962;29:121-8.

2. Spock B. Baby and child care. New York (NY): Meredith Press; 1968.

3. Foxx RM, Azrin NH. Dry pants: a rapid method of toilet training children. Behav Res Ther 1973;11:435-42.

4. Butler JF. The toilet training success of parents after reading Toilet Training in Less than a Day. Behavior Therapy 1976;7:185-91.

5. Sun M, Rugolotto S. Assisted infant toilet training in a Western family setting. J Dev Behav Pediatr 2004;25:99-101.

6. Vermandel A, Weyler J, De Wachter S, et al. Toilet training of healthy young toddlers: a randomized trial between a daytime wetting alarm and timed potty training. J Dev Behav Pediatr 2008; 29:191-6.

7. Kiddoo D, Klassen TP, Lang ME, et al. The effectiveness of different methods of toilet training for bowel and bladder control. Evidence report/technology assessment no. 147. Rockville (MD): Agency for Healthcare Research and Quality; 2006.

8. Candelora K. An evaluation of two approaches to toilet training normal children. Diss Abstr 1977;38:(5-B).

9. Taubman B, Blum NJ, Nemeth N. Stool toileting refusal: a prospective intervention targeting parental behavior. Arch Pediatr Adolesc Med 2003; 157:1193-6.

10. Matson JL, Ollendick TH. Issues in toilet training normal children. Behav Ther 1977;8:549-53.

11. Wolraich ML, Tippins S. American Academy of Pediatrics guide to toilet training. New York (NY): Bantam Books; 2003.

12. Community Paediatrics Committee, Canadian Paediatric Society. Toilet learning: anticipatory guidance with a child-oriented approach. Paediatr Child Health 2000;5:333-44.

13. Bakker E, Van Gool JD, Van Sprundel M, et al. Results of a questionnaire evaluating the effects of different methods of toilet training on achieving bladder control. BJU Int 2002;90:456-61.

14. Blum NJ, Taubman B, Nemeth N. Why is toilet training occurring at older ages? A study of factors associated with later training. J Pediatr 2004;145:107-11

15. Barone JG, Jasutkar N, Schneider D. Later toilet training is associated with urge incontinence in children. J Pediatr Urol 2009;5: 458-61.

16. Chen JJ, Ahn HJ, Steinhardt GF. Is age at toilet training associated with the presence of vesicoureteral reflux or the occurrence of urinary tract infection? J Urol 2009;182:268-71.

17. da Fonseca EM, Santana PG, Gomes FA, et al. Dysfunction elimination syndrome: Is age at toilet training a determinant? $J$ Pediatr Urol 2011;7:332-5.

18. Yang SS, Zhao LL, Chang SJ. Early initiation of toilet training for urine was associated with early urinary continence and does not appear to be associated with bladder dysfunction. Neurourol Urodyn 2011 Mar. 10. doi: 10.1002/nau.20982. [Epub ahead of print]

19. Joinson C, Heron J, Von Gontard A, et al. A prospective study of age at initiation of toilet training and subsequent daytime bladder control in school-age children. J Dev Behav Pediatr 2009;30: $385-93$

Affiliation: Darcie A. Kiddoo is with the Divisions of Pediatric Surgery and Urology, Department of Surgery, University of Alberta, Edmonton, Alta. 